Rozansky, R., Bachrach, U. \& Grossowicz, N. (1954). J. gen. Microbiol., 10, 11-16.

\title{
Studies on the Antibacterial Action of Spermine
}

\author{
By R. ROZANSKY, U. BACHRACH AND N. GROSSOWICZ \\ Department of Clinical Microbiology and Department of Bacteriology, \\ Hebrew University-Hadassah Medical School, Jerusalem, Israel
}

SUMMARY: Spermine was found to inhibit the growth of various micro-organisms. The most susceptible were Staphylococcus aureus and Staph. albus, Neisseria gonorrhoeae and N. meningitidis, and to a lesser degree Bacillus anthracis. The Enterobacteriaceae were relatively resistant. The action of spermine was enhanced by an increase in $\mathrm{pH}$ of the medium. The antibacterial effect was bactericidal; it was slowed but not prevented by a decrease in temperature from 37 to $6^{\circ}$. The nutrients of various media influenced the action of spermine.

Spermine, a biological polyamine, is a substance of controversial nature. It has been shown to possess growth-inhibiting properties against various microorganisms (Bichowsky-Slomnitzki, 1948; Gurevitch, Rozansky, Weber, Brzezinsky \& Eckerling 1951; Hirsch \& Dubos, 1952; Rozansky, Gurevitch, Brzezinsky \& Eckerling, 1949) and growth-promoting activity for Haemophilus parainfluenzae (Herbst \& Snell, 1948). It has also been found to counteract the antibacterial effect of atebrine, propamidine and quinine on Escherichia coli (Silverman \& Evans, 1943, 1944; Miller \& Peters, 1945). Spermine is widespread in human and animal body tissue (Guggenheim, 1940; Harrison, 1933). Its role, if any, as an antibacterial agent which affords natural resistance to the body, is unknown. Further studies of this material therefore seemed worthwhile. The present investigation is concerned with the following aspects of the antibacterial action of spermine: mode of action; influence of $\mathrm{pH}$; influence of temperature; sensitivity of different bacteria.

\section{MATERIALS AND METHODS}

Spermine tetrahydrochloride (Hoffmann La Roche) was used throughout the experiments. The micro-organism studied most extensively was Staphylococcus aureus no. 23, a haemolytic coagulase and mannitol positive strain. The other bacteria used are listed in Table 2.

Antibacterial assays of spermine were made by $(a)$ serial dilution and $(b)$ the cup method. Serial dilutions of spermine were made in Wassermann tubes $(13 \times 100 \mathrm{~mm}$.) containing $2 \mathrm{ml}$. of Difco nutrient broth. Controls without spermine were included in all experiments. The cup method was the same as previously reported (Rozansky et al. 1949). Difco nutrient agar was used except when otherwise specified.

\section{RESULTS}

Influence of $\mathrm{pH}$ value of the medium on the growth inhibition of Staph. aureus by spermine

The antibacterial activity of spermine rose gradually with the increase of the $\mathrm{pH}$ of the medium (see Fig. 1). Change in $\mathrm{pH}$ value from 6.2 to 8.75 decreased 
the amount of spermine required to obtain complete inhibition of Staph. aureus from $1000 \mu \mathrm{g}$. $/ \mathrm{ml}$. to $2 \mu \mathrm{g}$. $/ \mathrm{ml}$. The growth of the test organism in the control tubes, i.e. in the absence of spermine, was almost unaffected by these changes in $\mathrm{pH}$ value.

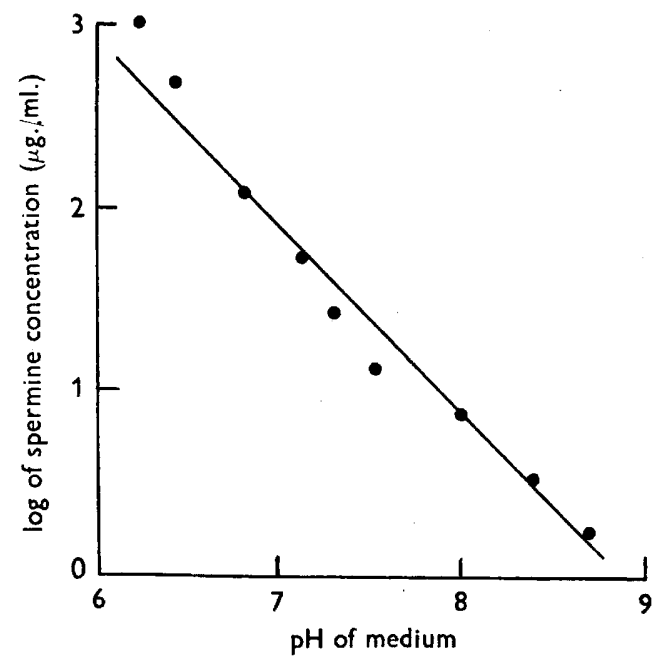

Fig. 1. Minimal concentration of spermine inhibiting the growth of Staph. aureus at various pH values of the medium. Size of inoculum $c .10^{4}$ cells $/ \mathrm{ml}$. Medium: Difco nutrient broth. Results read after $48 \mathrm{hr}$. incubation. Inhibition i.e. no visible growth.

\section{Bactericidal effect of spermine}

In experiments with Staph. aureus 23, the size of inoculum did not affect appreciably the inhibitory activity of spermine. A 100- and 10,000-fold increase of the inoculum required a twofold and eightfold increase of spermine respectively.

These results suggested that the drug exerted a bactericidal effect. In order to test this, Staph. aureus was inoculated into flasks of Difco nutrient broth (pH 7.7) containing $25 \mu \mathrm{g} . / \mathrm{ml}$. and $50 \mu \mathrm{g} . / \mathrm{ml}$. of spermine and into control flasks without spermine. The flasks were incubated at $37^{\circ}$ and at varying intervals of time (Table 1) samples were taken for the determination of viable counts. The pour-plate method was used, and plates were incubated for $48 \mathrm{hr}$. at $37^{\circ}$. All counts were performed in triplicate.

At $37^{\circ}$ (see Table 1) $25 \mu \mathrm{g}$. spermine/ml. for $3 \mathrm{hr}$. killed $70 \%$ of the staphylococci. Fifty $\mu$ g. spermine $/ \mathrm{ml}$. were even more effective, killing more than $99 \%$ of the bacteria in $3 \mathrm{hr}$. After $10 \mathrm{hr}$. incubation all flasks containing 25 and $50 \mu \mathrm{g}$. spermine $/ \mathrm{ml}$. were sterile.

In order to determine whether spermine was effective against non-multiplying bacteria, broth samples containing varying concentrations of spermine were inoculated with Staph. aureus 23 . The flasks were kept at $6^{\circ}$ and the number of surviving bacteria was determined after 24,72 and $96 \mathrm{hr}$. by the plate-count technique. Controls without spermine were run simultaneously. 
Antibacterial action of spermine

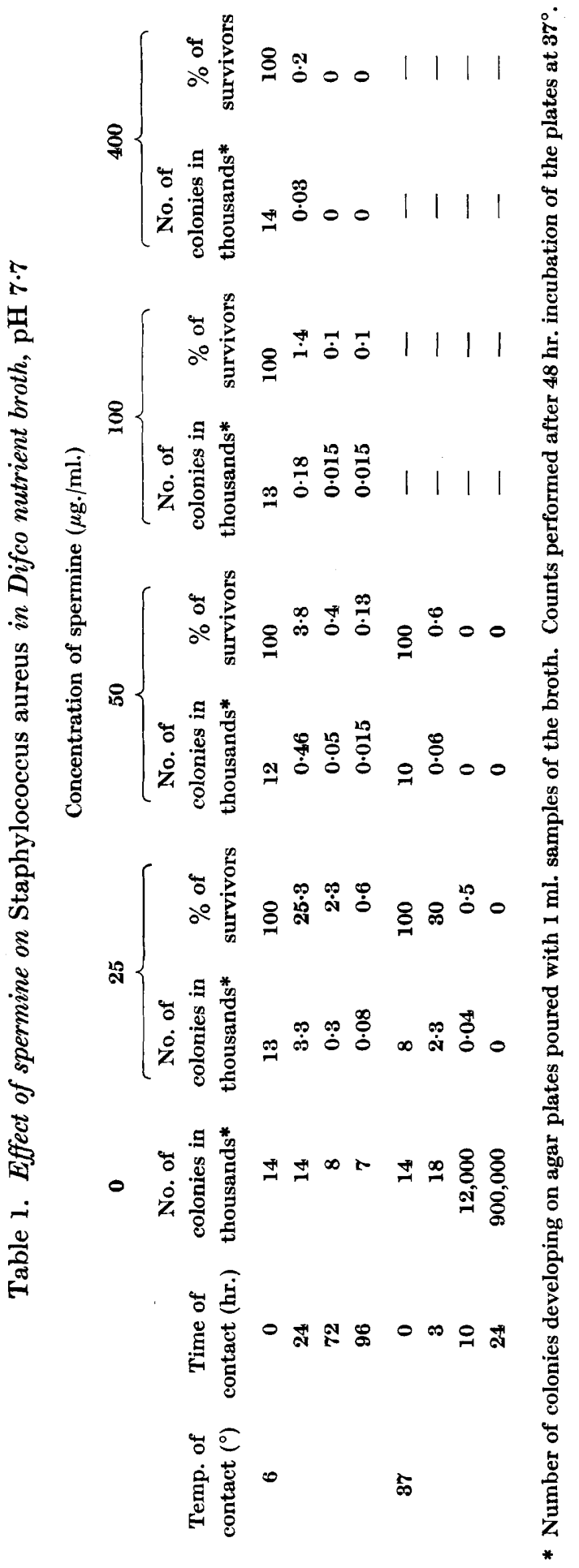


It is seen from Table 1 that spermine killed the staphylococci in the cold. The action at $6^{\circ}$ was however markedly slower than at $37^{\circ}, 25 \mu \mathrm{g} . / \mathrm{ml}$. killed about $75 \%$ of the staphylococci in $24 \mathrm{hr}$; $50 \mu \mathrm{g} . / \mathrm{ml}$. killed $96 \%$ of the cells in the same time; $400 \mu \mathrm{g} . / \mathrm{ml}$. killed $99 \cdot 8 \%$ after $24 \mathrm{hr}$.

\section{Susceptibility of different micro-organisms to spermine}

Table 2 shows that the organisms most sensitive to the inhibitory action of spermine were staphylococci, both aureus and albus types. In Difco nutrient agar at $\mathrm{pH} \mathrm{7.3}$ and $7 \cdot 5,50$ and $25 \mu \mathrm{g}$. of spermine, respectively, diluted in $0 \cdot 1 \mathrm{ml}$. of saline were required to produce a clear zone of inhibition (not less than $12 \mathrm{~mm}$. in diameter) by the cup technique. In Difco nutrient broth at the same $\mathrm{pH}$ values (i.e. $7 \cdot 3$ and $7 \cdot 5$ ) a concentration of 30 and $15 \mu \mathrm{g} . / \mathrm{ml}$. caused full inhibition.

Neisseria gonorrhoeae and $N$. meningitidis tested on glucose starch agar (Difco) and ascites agar were inhibited to a similar extent to that found with staphylococci.

Various Gram-negative rods of the family Enterobacteriaceae were only slightly affected by the drug. Shigella flexneri, however, was found to be quite sensitive at an alkaline $\mathrm{pH}$. Haemolytic streptococci and Corynebacterium hofmanni were tested for their sensitivity to spermine in nutrient broth enriched with brain heart infusion (4 parts Difco nutrient broth and 1 part Difco brain heart infusion broth) and were found to be inhibited by $250 \mu \mathrm{g}$./ spermine ml. (Table 2).

\section{COMMENT}

The degree of inhibition of bacterial growth by spermine depended on several factors. One of these was the $\mathrm{pH}$ of the medium. In Fig. 1 an almost straight line was obtained when the inhibitory activity of spermine on Staph. aureus 23 was plotted against the $\mathrm{pH}$ of the medium. It seemed, therefore, that the undissociated molecule rather than the ionized form was responsible for the antibacterial properties. The influence of the $\mathrm{pH}$ was less marked with Bacillus anthracis and Sh. flexneri and still less evident with the more resistant enterobacteriaceae and Streptococcus faecalis (Table 2). Hirsch \& Dubos (1952) found that the inhibition of growth of Mycobacterium tuberculosis, an organism highly susceptible to spermine, was independent of the $\mathrm{pH}$ value of the medium between $6 \cdot 3$ and $7 \cdot 4$.

The action of spermine was primarily bactericidal and was also evident against non-multiplying organisms. Hirsch \& Dubos (1952) have demonstrated the bactericidal effect of spermine for Myco. tuberculosis.

The activity of spermine was influenced by the medium employed. Organisms grown in brain-heart infusion were much less affected than in nutrient broth (Table 2). The spermine antagonizing effect of Bacto stock agar has been described previously (Gurevitch et al. 1951). It is possible that the relatively high resistance of haemolytic streptococci and $C$. hoffmani which were tested in brain-heart infusion was due to the presence of spermine antagonists in these complex media. 
Table 2. Inhibition of growth of various micro-organisms by spermine

Strain

Staph. aureus 23

Staph. albus B

Staph. albus $\mathbf{H 5}$

B. anthracis

Sh. flexneri 1150

E. coli 055

Sal. typhi

Str. faecalis

Str. faecalis 19

Myco. phlei

C. hofmannii

Str. haemolyticus

N. gonorrhoeae

N. meningitidis
Medium

Nutrient broth or agar

Nutrient broth or agar

Nutrient broth or agar

Nutrient broth or agar

Nutrient broth or agar

Nutrient broth or agar

Nutrient broth or agar

Nutrient broth or agar

Nutrient broth or agar

4 parts nutr. br. and 1 part brain-heart broth

4 parts nutr. br. and 1 part $\mathbf{7 \cdot 9}$ brain-heart broth

Nutrient broth or agar

Nutrient broth or agar

Nutrient broth or agar

Nutrient broth or agar

Nutrient broth or agar

Nutrient broth or agar

Nutrient broth or agar

Nutrient broth or agar

Nutrient broth or agar

Nutrient broth or agar

Nutrient broth or agar

Nutrient broth or agar

Nutrient broth or agar

Nutrient broth or agar

Nutrient broth or agar

Nutrient broth or agar

Nutrient broth or agar

Nutrient broth or agar

Nutrient broth or agar

Nutrient broth or agar

Nutrient broth or agar

Nutrient broth or agar

Nutrient broth or agar

Nutrient broth or agar

4 parts nutr. br. and 1 part brain-heart broth

4 parts nutr. br. and 1 part brain-heart broth

Dextrin starch agar

Ascites agar

Dextrin starch agar

Ascites agar

$6 \cdot 8$

$8 \cdot 0$

$6 \cdot 8$

$8 \cdot 0$

$6 \cdot 2$

$6 \cdot 8$

$7 \cdot 8$

$7 \cdot 9$

8.7

$6 \cdot 4$

$8 \cdot 0$

$8 \cdot 5$

$8 \cdot 8$

$6 \cdot 8$

$8 \cdot 0$

$6 \cdot 8$
Concentration of

spermine showing

inhibition using

$\begin{array}{ccc}\begin{array}{c}\mathrm{pH} \text { of } \\ \text { medium }\end{array} & \begin{array}{c}\text { Dilution } \\ \text { method } \\ \mu \mathrm{g} . / \mathrm{ml} . *\end{array} & \begin{array}{c}\text { Cup } \\ \text { method } \\ \mu \mathrm{g} . / 0 \cdot 1 \text { ml. } \dagger \text { Remarks }\end{array}\end{array}$

1000

500

125

60

30

15

8

6

2

250

60

$7 \cdot 0$

$7 \cdot 3$

$6 \cdot 8 \quad 1000$

$7 \cdot 3 \quad 1000$

$6 \cdot 8 \quad 1000$

$8.0 \quad 1000$

$6 \cdot 8 \quad 1000$

$7 \cdot 7 \quad 1000$

$7 \cdot 1$

$7 \cdot 1$

250

$\begin{array}{ll}\text { - } & \text { 2 strains } \\ & \\ \mathbf{5 0} & \text { 5 strains } \\ \mathbf{5 0} & \text { 2 strains } \\ \mathbf{5 0} & \text { 4 strains } \\ \mathbf{5 0} & \text { 2 strains }\end{array}$

* Concentration of spermine causing inhibition of visible growth after $48 \mathrm{hr}$. incubation at $37^{\circ}$. Inoculum $c .10,000$ organisms $/ \mathrm{ml}$. Twofold dilution technique.

$\dagger$ Concentration of spermine causing a clear inhibition zone of not less than $12 \mathrm{~mm}$. in diameter, $0 \cdot 1 \mathrm{ml}$. of samples containing the specified amounts were introduced into the cups. 
The authors wish to thank Mrs R. Kushnir-Yeivin, M.Sc., for assistance in some of the experiments. The tests with Neisseria were performed by one of us (R.R.) at the Statens Seruminstitut in Copenhagen. Appreciation is expressed to Dr J. Ørskov, Director of the Institute, and to Dr A. Reyn, Chief of the serodiagnostic department, for facilities provided, and to Dr J. Bang for valuable advice and assistance.

\section{REFERENCES}

Bichowsky-Slomnitzki, L. (1948). The effect of aromatic diamidines on bacterial growth. J. Bact. 55, 27.

Guggenheim, M. (1940). Die biogenen Amine, 3rd edition, p. 229. Basel, New York: S. Karger.

Gurevitch, J., Rozansky, R., Weber, D., Brzezinsky, A. \& Eckerling, B. (1951). Role of spermine in the inhibition of Staphylococcus aureus by human semen. J. clin. Path. 4, 360.

Harrison, G. A. (1933). The approximate determination of spermine in single human organs. Biochem. J. 27, 1152.

Herbst, E. J. \& Sneld, E. E. (1948). Putrescine as a growth factor for Hemophilus parainfluenzae. J. biol. Chem. 176, 989.

Hirsch, J. G. \& Dubos, R. J. (1952). The effect of spermine on tubercle bacilli. J. exp. Med. 95, 191.

Miller, A. K. \& Peters, L. (1945). The antagonism by spermine and spermidine of the antibacterial action of quinacrine and other drugs. Arch. Biochem. 6, 281.

Rozansky, R., Gurevitch, J., Brzezinsky, A. \& Eckerling, B. (1949). Inhibition of the growth of Staphylococcus aureus by human semen. J. lab. clin. Med. 34, 1526.

Silverman, M. \& Evans, Jun. E. A. (1943). The effects of spermidine and other polyamines on growth inhibition of Escherichia coli by atabrine. J. biol. Chem. 150, 263.

Silverman, M. \& Evans, Jun. E. A. (1944). Effect of spermine, spermidine and other polyamines on growth inhibition of Escherichia coli by atabrine. J. biol. Chem. 154, 521 . 